\title{
Livedoid vasculopathy as a marker of systemic disease: report of two cases*
}

\author{
Raquel Sucupira Andrade Lima ${ }^{1}$ \\ Carolina Talhari ${ }^{1,2,3}$ \\ Antônio Pedro Mendes Schettini ${ }^{1}$
}

\author{
Gustavo Ávila Maquiné ${ }^{1}$ \\ Isabel Cristina Lima Encarnação ${ }^{1}$ \\ Mônica Santos ${ }^{1,2,3}$
}

Abstract: The livedoid vasculopathy is an obstructive vascular process of etiology not yet fully known, being possibly associated with several prothrombotic events. It is clinically characterized by the presence of painful and recurring purpuric lesions, which usually suffer ulceration and evolve with formation of white atrophic scars usually located in the lower limbs. Two cases are here reported of painful ulcerated lesions on the lower limbs, in which the identification of VL enabled the diagnosis of systemic diseases.

Keywords: Atrophy; Leg ulcer; Skin diseases, vascular; Thrombosis

\section{INTRODUCTION}

Livedoid vasculopathy (LV) is an obstructive vascular process of etiology not yet fully known, possibly associated with several prothrombotic events, initially described by Millian, in 1929, who designated it as white atrophy. ${ }^{1}$ In 1967, Bard and Winkelman reported livedoid vasculopathy in patients with segmental hyalinizing alteration of small dermal vessels. ${ }^{2}$ For a long time, the term "livedoid vasculitis" was used as a synonym of the disease, but it is no longer accepted, for findings compatible with vasculitis are not present in the histological exam. ${ }^{3}$ Two cases with painful ulcerated lesions on the lower limbs are reported, in which the identification of VL enabled the diagnosis of systemic diseases.

\section{CASE REPORT}

Case 1 - Female patient, 27 years old, for seven years had outbreaks of painful ulcers on the lower limbs (Figure 1). Case 2 - Female patient, 29 years old, for four years had intensely painful purpuric lesions, which evolved with localized ulcerations on legs and feet (Figure 2). At the physical examination, both presented ulcers with irregular borders, clean back- ground, in different progression stages, some of them with a white-pearly coloration, in addition to scars on lower limbs. The histopathological exams of both cases showed segmental hyaline thickening of vessel walls, fibrinoid deposits and hyaline thrombi in the vascular lumen, red blood cell extravasation and discrete inflammatory infiltrate, confirming the LV diagnosis (Figure 3). An extensive investigation of autoimmune diseases and prothrombotic states was performed. In case 1, the lipoprotein-a ( $\mathrm{Lp}(\mathrm{a}))$ was positive $(123 \mathrm{mg} / \mathrm{dL}$ - reference value $<30)$. In case 2 , anticardiolipin antibody was positive in two samples with interval of 12 weeks. This patient also reported previous history of abortions with less than 10 weeks, characterizing Antiphospholipid syndrome (APS). Both cases were prescribed aspirin and pentoxifylline with complete cicatrization of lesions in case 1 . Case 2 was followed-up in conjunction with rheumatology and prescribed pulse therapy with cyclophosphamide and oral prednisone in an immunosuppressive dose. Both patients are in clinical remission, with periodical ambulatory follow-up, after 12 (case 1) and 18 months (case 2) since initial diagnosis (Figure 4). 


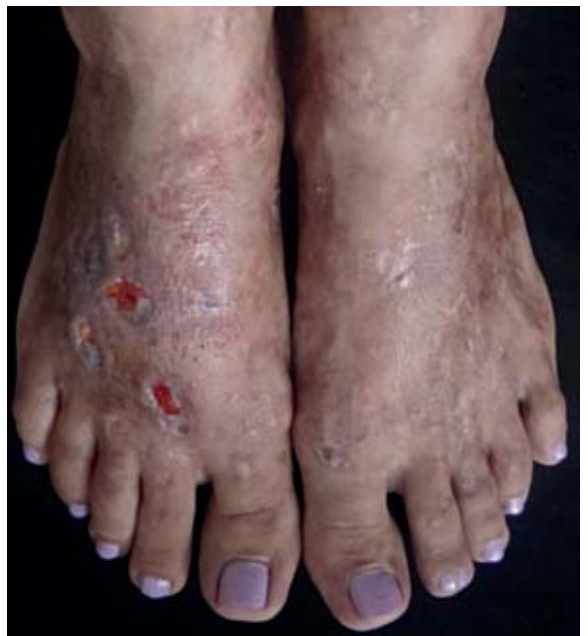

FIGURE 1: Case 1: $\mathrm{U} l \mathrm{c}$ e r a t e d lesions and atrophic scars located on the

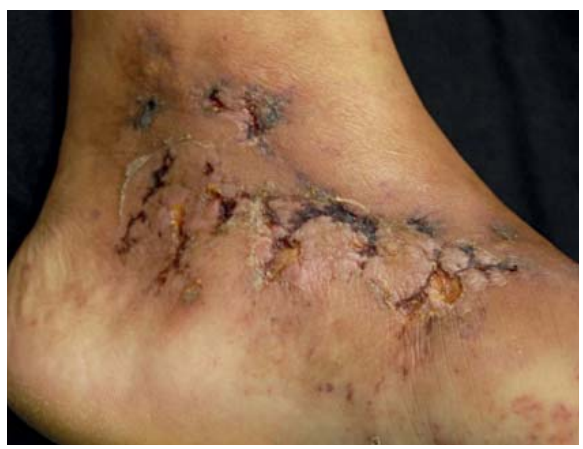

FIGURE 2: Case 2: Erythematouspurpuric lesions and ulceration located in medial and malleolar region of left foot

\section{DISCUSSION}

$\mathrm{LV}$ is clinically characterized by the presence of painful and recurring purpuric lesions, which usually suffer ulceration, evolving with formation of whitish atrophic scars, located on the lower limbs. The disease usually progresses in outbreaks, with periods of seasonal exacerbation. ${ }^{4}$ Its pathogenesis is not yet fully understood, however the vaso-occlusive theory is currently the most widely accepted. Some factors underlie this theory: the histopathological analysis with the presence of hyaline thrombi in most cases, good response to the treatment of prothrombotic states and the several reports associated with thrombophilia. ${ }^{5,6}$ More rarely, the disease has been associated with the lipoprotein-a, which is considered an independent risk factor for coronary artery disease. ${ }^{7,8}$ The reporting of these cases reinforce this association since patient 1 presents LV associated to high levels of $L p(a)$ and patient 2 was diagnosed with APS from the identification of LV. The differential diagnosis of LV is done mainly with cutaneous vasculitides and anticoagulant drugs can be employed for its treatment (warfarin, heparin, or fibrinolytics) as well as antiplatelet agents such as acetylsalicylic acid. Vasodilating drugs, such as pentoxifylline, can still be used. In cases associated with autoimmune diseases, immunosuppressants are also used. ${ }^{9,10}$
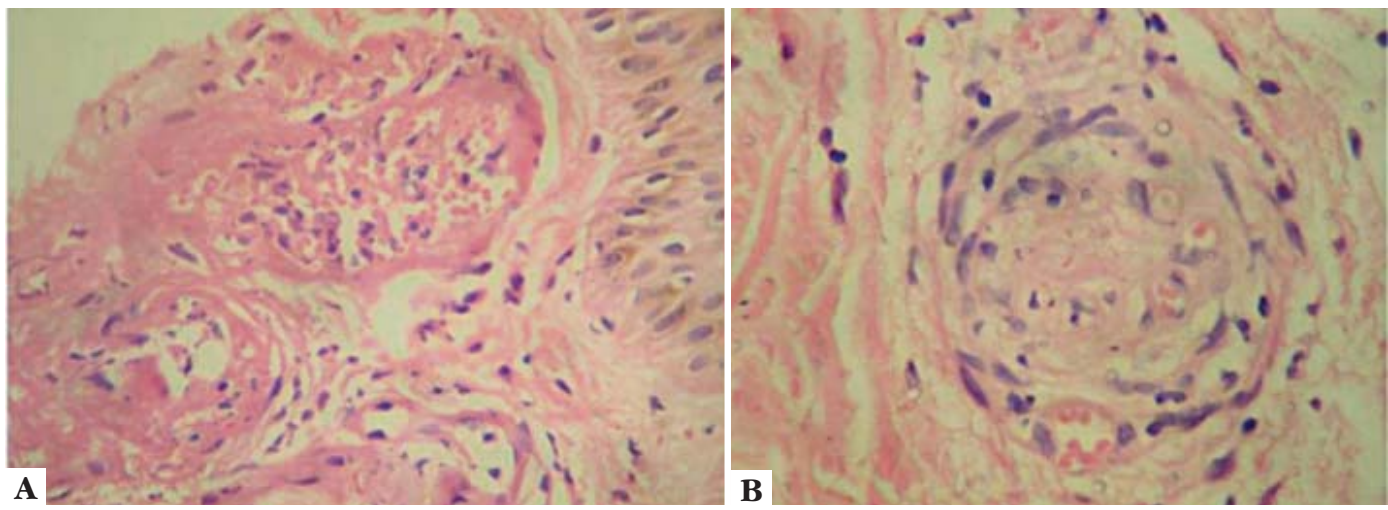

FiguRE 3:

Fibrinoid deposits with hyaline thickening of vessel walls; extravasation of red blood cells and hyaline thrombi into vascular lumen (HE 200 and 400x)
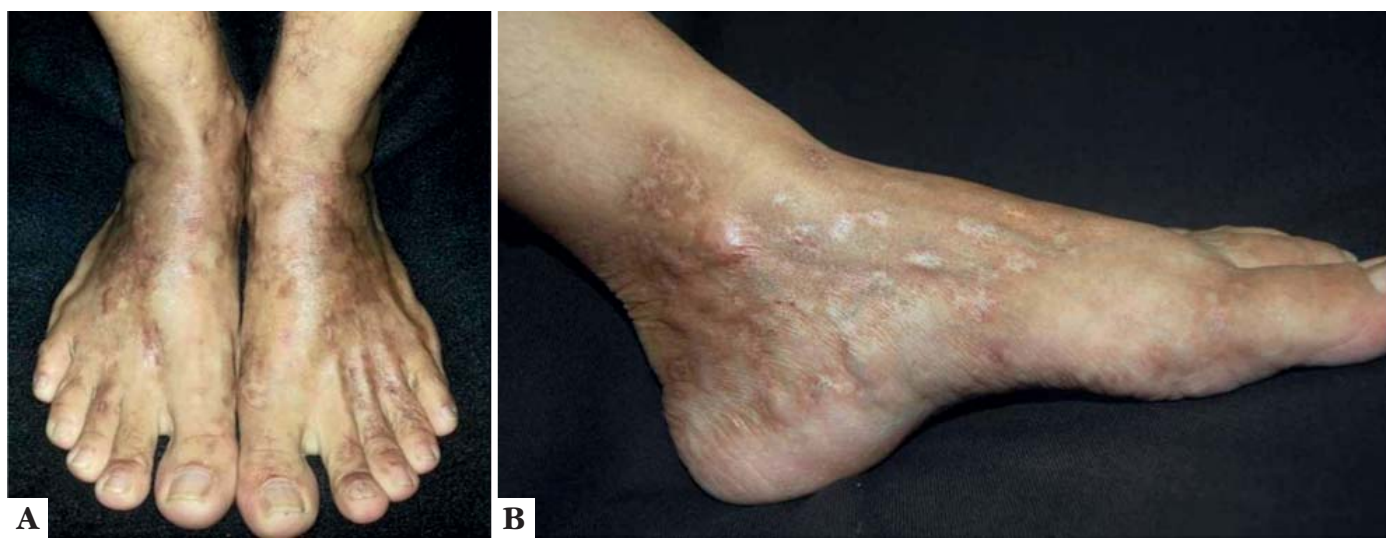

FigURE 4:

A (case 1) and $\mathbf{B}$ (case 2): cicatrization of ulcers, with some atrophic lesions and residual A hyperchromia 


\section{REFERENCES}

1. Chang D, Rajiv M. Livedoid Vasculopathy. Cutis. 2012;90:179, 181-2.

2. Gonzalez-Santiago TM, Davis MD. Update of management of connective tissue diseases: livedoid vasculopathy. Dermatol Ther. 2012;25:183-94.

3. Pulido-Pérez A, Avilés-Izquierdo JA, Suárez-Fernández R. Cutaneous Vasculitis. Actas Dermosifiliogr. 2012;103:179-91.

4. Criado PR, Rivitti EA, Sotto MN, Valente NY, Aoki V, Carvalho JF, et al. Livedoid vasculopathy: an intringuing cutaneous disease. An Bras Dermatol. 2011;86:961-77.

5. Feng SY, Jin PY, Shao CG. The significance of anticardiolipin antibody and immunologic abnormality in livedoid vasculitis. Int J Dermatol. 2011;50:21-3.

6. Jorge AD, Fantini BC, Rivitti EA, Benabou JE, Vasconcelos C, Criado PR. Frequency analysis of thrombophilia in patients with atrophie blanche. An Bras Dermatol. 2007;82:25-33.

7. Criado PR, Rivitti EA, Sotto MN, de Carvalho JF. Livedoid vasculopathy as a coagulation disorder. Autoimmun Rev. 2011;10:353-60.

8. Vasconcelos R, Criado PR, Belda W Jr. Livedoid Vasculopathy secondary to high levels of lipoprotein(a). Br J Dermatol. 2011:164:1111-3.

9. Haunson GT, Judy DW, Prall NC, Miller RA. Livedoid Vasculopathy: Review of pathogenesis, clinical presentation, diagnostic workup, and treatment. Cutis. 2012;90:302-6

10. Davis MD, Wysokinski WE. Ulcerations caused by livedoid vasculopathy associated with a prothrombotic state: response to warfarin. J Am Acad Dermatol. 2008;58:512-5

\author{
MAILING ADDRESS: \\ Mônica Santos \\ Avenida Codajas, 25 \\ Cachoeirinha \\ 69065-130 - Manaus - AM \\ Brazil \\ E-mail:m.n.souza.santos@gmail.com
}

How to cite this article: Lima RSA, Maquiné GA, Talhari C, Encarnação ICL, Schettini APM, Santos M. Livedoid vasculopathy as a marker of systemic disease: report of two cases. An Bras Dermatol. 2014;89(5):822-4. 